\title{
Survival of patients on dialysis having off-pump versus on-pump coronary artery bypass surgery in the United States
}

\author{
Gautam R. Shroff, MD, ${ }^{\mathrm{a}}$ Shuling Li, MS, ${ }^{\mathrm{b}}$ and Charles A. Herzog, MD ${ }^{\mathrm{a}, \mathrm{b}}$
}

Background: Patients on dialysis sustain at least a threefold higher in-hospital mortality rate and markedly higher long-term mortality following coronary artery bypass graft surgery than the general population. Smaller studies have suggested that dialysis patients have superior outcomes with off-pump compared with on-pump coronary artery bypass surgery.

\begin{abstract}
Methods: From the United States Renal Data System database, 13,085 patients on dialysis having first coronary artery bypass surgery between 2001 and 2006 were identified. Of these, 2335 (17.8\%) had off-pump coronary artery bypass surgery. The Kaplan-Meier method was used to estimate survival of patients having off-pump coronary artery bypass and patients having on-pump coronary artery bypass. A Cox proportional hazards model was used to assess effects of off-pump coronary artery bypass on mortality with adjustment for baseline patient characteristics.
\end{abstract}

Results: Off-pump coronary artery bypass surgery was associated with significantly reduced all-cause mortality compared with on-pump coronary artery bypass surgery (hazard ratio $0.92,95 \%$ confidence interval $0.86-0.99$, $P=.02)$. The observed survival benefit was most notable in the first year after surgery $(70.3 \%$ vs $68.7 \%)$ and was lost 2 years after surgery $(55.4 \%$ vs $55.2 \%)$. No difference was noted in the in-hospital mortality rate with offpump coronary artery bypass surgery versus on-pump coronary artery bypass surgery $(9.7 \%$ vs $11.0 \%, P=.06)$. Cardiac mortality during the follow-up period was similar (23.6\% vs $23.8 \%$; adjusted hazard ratio $0.95,95 \%$ confidence interval $0.86-1.04, P=.26)$. Use of internal thoracic grafts was independently associated with improved survival after coronary artery bypass surgery (hazard ratio, $0.92 ; 95 \%$ confidence interval, $0.87-0.98$, $P=.0057)$.

Conclusions: Patients on dialysis sustain high in-hospital and 2-year mortality rates after coronary artery bypass surgery. Off-pump coronary artery bypass is associated with modestly increased survival compared with onpump coronary artery bypass, a benefit most marked early after off-pump coronary artery bypass. (J Thorac Cardiovasc Surg 2010;139:1333-8)

Patients with chronic kidney disease (CKD) are at markedly high risk for cardiovascular morbidity and mortality. Estimated glomerular filtration rate is strongly, inversely, and independently related to all-cause mortality, cardiovascular events, and rates of hospitalization. ${ }^{1}$ Patients with CKD who have percutaneous and surgical coronary revascularization sustain markedly higher long-term all-cause mortality than patients without CKD. ${ }^{2}$ One-year mortality for general Medicare patients without CKD who had coronary artery bypass graft (CABG) surgery in 2004 was $10 \%$ versus

\footnotetext{
From the Department of Medicine, ${ }^{\mathrm{a}}$ Hennepin County Medical Center, University of Minnesota, Minneapolis, Minn; and Cardiovascular Special Studies Center, ${ }^{\mathrm{b}}$ United States Renal Data System, Minneapolis, Minn.

Disclosures: This study was performed as a deliverable under Contract No. HHSN267200715003C (National Institute of Diabetes and Digestive and Kidney Diseases, National Institutes of Health, Bethesda, Md). The data reported have been supplied by the United States Renal Data System. The interpretation and reporting of these data are the responsibility of the authors and in no way should be seen as an official policy or interpretation of the US government.

Received for publication Feb 10, 2009; revisions received May 20, 2009; accepted for publication Aug 10, 2009; available ahead of print Oct 26, 2009.

Address for reprints: Charles A. Herzog, MD, Cardiovascular Special Studies Center, United States Renal Data System, 914 South 8th Street, Suite S-406, Minneapolis MN 55404 (E-mail: cherzog@usrds.org).

$0022-5223 / \$ 36.00$

Copyright (C) 2010 by The American Association for Thoracic Surgery

doi:10.1016/j.jtcvs.2009.08.021
}

$22 \%$ for patients with CKD without end-stage renal disease (ESRD). ${ }^{3}$ In comparison, 1-year mortality for patients on dialysis was $33 \%{ }^{4}{ }^{4}$ Thus, mortality risk increases as renal insufficiency worsens.

Off-pump coronary artery bypass (OPCAB) surgery is potentially attractive for patients likely to have severe vasculopathy, such as patients with ESRD. Its principal physiologic advantages over on-pump CABG surgery include the ability to avoid the deleterious consequences of the systemic inflammatory response incited by the bypass circuit ${ }^{5}$ and atheroembolism caused by aortic cannulation and crossclamping. ${ }^{6}$

Unfortunately, available literature regarding translating these physiologic advantages into improved clinical outcomes has been contradictory. The mortality benefit with OPCAB noted in larger registry data ${ }^{7,8}$ has not been reproduced in smaller, randomized trials. ${ }^{9,10}$ In particular, no survival advantage with OPCAB has been shown for low-risk patients. ${ }^{10}$ This inconsistency in the literature raises the question of whether high-risk patients may benefit from OPCAB but may have been underrepresented in previous studies. Indeed, some studies suggest greater benefit of OPCAB for high-risk patients, especially elderly patients or patients with diabetes, previous stroke, or severe vascular disease, and patients having repeat $\mathrm{CABG}$. $^{7,8,11,12}$ 


$\begin{aligned} & \text { Abbreviations and Acronyms } \\ & \text { CABG }=\text { coronary artery bypass graft } \\ & \text { CI }=\text { confidence interval } \\ & \text { CKD }=\text { chronic kidney disease } \\ & \text { CMS }=\text { Centers for Medicare \& Medicaid } \\ & \text { CPT }=\text { Current Procedural Terminology } \\ & \text { ESRD }=\text { end-stage renal disease } \\ & \text { ICD-9-CM }= \text { International Classification of } \\ & \text { Diseases, Ninth Edition, Clinical } \\ & \text { Modification } \\ & \text { OPCAB }= \text { off-pump coronary artery bypass } \\ & \text { PCI }=\text { percutaneous coronary intervention } \\ & \text { USRDS }= \text { United States Renal Data System }\end{aligned}$

Patients on dialysis constitute a high-risk population, sustaining at least a threefold higher in-hospital mortality rate and higher rates of nonfatal complications after $\mathrm{CABG}$ than the general population. ${ }^{13}$ Historically, patients on long-term dialysis have been modestly represented in studies comparing OPCAB and on-pump CABG. ${ }^{7,9,12}$ Limited published data for patients on dialysis suggest superior outcomes with OPCAB. ${ }^{14,15}$ The objectives of this study were to compare survival for patients on dialysis having OP$\mathrm{CAB}$ versus on-pump $\mathrm{CABG}$ and to determine predictors of survival for patients on dialysis having CABG.

\section{METHODS}

\section{Database and Patients}

Data for this study are from the United States Renal Data System (USRDS) database $(\mathrm{n}=1,910,161)$. The accuracy of these data has been previously validated. ${ }^{16}$ Institutional review board approval was obtained. Patients on dialysis who had first CABG (International Classification of Diseases, Ninth Edition, Clinical Modification [ICD-9-CM] procedure code 36.1) between January 1, 2001, and December 31, 2006, after renal replacement therapy initiation, were identified for study inclusion. Those who had CABG without cardiopulmonary bypass (OPCAB) were further identified by Current Procedural Terminology (CPT) code 00566. To assess for possible crossover from the OPCAB to the on-pump CABG arm, CPT code 00562 (with pump oxygenator) was assessed during the hospitalization for OPCAB surgery. Internal thoracic graft use and number of vessels bypassed were identified by ICD-9-CM codes 36.15, 36.16, and 36.11-36.19.

All eligible patients had been diagnosed with ESRD at least 90 days before CABG, were aged $\geq 20$ years on the date of surgery, and resided in the 50 US states, Washington DC, or the US territories. All patients had Medicare as primary payer. Patients having concomitant valve surgery or with prior $\mathrm{CABG}$ were excluded from the analysis.

Patient baseline characteristics included demographic factors (age, sex, race, ESRD duration, ESRD cause, dialysis modality, prior renal transplant), surgical variables (year of surgery, number of vessels bypassed, use of internal thoracic graft), length of hospital stay for the CABG surgery admission, and comorbid conditions. Comorbid conditions were determined from the Centers for Medicare \& Medicaid (CMS) ESRD Medical Evidence Report (form CMS-2728) and Medicare claims using a previously published methodology ${ }^{17,18}$ and included acute myocardial infarction, congestive heart failure, other cardiac conditions, cerebrovascular accident/transient ischemic attack, diabetes, dysrhythmias, chronic obstructive pulmonary dis- ease, gastrointestinal bleeding, liver disease, cancer, and peripheral vascular disease.

The outcomes evaluated were all-cause mortality, a combined event of second CABG and all-cause mortality, and cardiac mortality. Cardiac mortality was determined using data derived from the ESRD Death Notification form (CMS-2746). Death ascribed to myocardial infarction, pericarditis (including cardiac tamponade), atherosclerotic heart disease, cardiomyopathy, cardiac arrhythmia, cardiac arrest (cause unknown), valvular heart disease, pulmonary edema due to exogenous fluid, and congestive heart failure were classified as being due to cardiac causes. ${ }^{2}$ For all-cause and cardiac mortality, patients were followed from the date of CABG to the earliest occurrence of death, 3 years after first CABG, or December 31, 2006. For the combined event of second $\mathrm{CABG}$ and all-cause mortality, patients were followed to the earliest occurrence of second CABG, death, 3 years after first CABG, or December 31, 2006. Patients were censored at renal transplant or loss to follow-up.

\section{Data Analysis}

Baseline characteristics of the OPCAB and on-pump CABG study populations were defined as categorical variables and presented as proportions. Differences were tested using the chi-square test. Length of stay for the CABG surgery admission was also presented as a continuous variable, and the difference between the 2 study groups was tested using the 2-sample $t$ test. In-hospital mortality was determined for both groups and the difference was tested using the chi-square test. Survival was estimated by the Kaplan-Meier method, and subgroup survival was compared by log-rank test. A Cox proportional hazards model was used to assess the effect of OP$\mathrm{CAB}$ on mortality risk compared with on-pump $\mathrm{CABG}$ with adjustment for patient baseline characteristics. All statistical analyses were performed using SAS for Windows, version 9 (SAS Institute Inc, Cary, NC).

\section{RESULTS}

We identified 13,085 patients on dialysis (11,977 on hemodialysis and 1108 on peritoneal dialysis) who had CABG surgery during the study period. Of these, 2335 $(17.8 \%)$ had OPCAB. For all-cause mortality, mean \pm standard deviation follow-up time was $16.9 \pm 13.0$ months for patients having OPCAB and $17.1 \pm 13.3$ months for patients having on-pump CABG. Similar mean follow-up times were observed for the combined event of second CABG and allcause mortality: $16.7 \pm 13.0$ months for patients having OP$\mathrm{CAB}$ and $17.0 \pm 13.3$ months for patients having on-pump CABG. The median follow-up time for death was 14.84 months for both groups. The median follow-up time for the combined event of death and second CABG was 14.57 months for patients having OPCAB and 14.61 months for patients having on-pump CABG.

Of the 2335 patients having OPCAB, $1050(45.0 \%)$ died, $552(23.6 \%)$ died of cardiac disease, $32(1.4 \%)$ had a second CABG, and $4.4 \%$ were censored for renal transplant and $0.2 \%$ for loss to follow-up. Of the 10,750 patients having on-pump CABG, 4993 (46.5\%) died, $2562(23.8 \%)$ died of cardiac disease, $123(1.1 \%)$ had a second CABG, and $5.6 \%$ were censored for renal transplant and $0.2 \%$ for loss to follow-up.

Patients having OPCAB were more likely than those having on-pump CABG to be older and to have peripheral vascular disease but not previous cerebrovascular accident/ transient ischemic attack (Table 1). Patients having OPCAB 
TABLE 1. Baseline characteristics of the study population

\begin{tabular}{|c|c|c|c|c|}
\hline \multirow[b]{2}{*}{ Characteristics } & \multicolumn{3}{|c|}{$\begin{array}{c}\text { Coronary artery } \\
\text { bypass graft surgery }\end{array}$} & \multirow[b]{2}{*}{$P^{*}$} \\
\hline & $\begin{array}{c}\text { All } \\
(n=13,085)\end{array}$ & $\begin{array}{c}\text { On-pump } \\
(n=10,750)\end{array}$ & $\begin{array}{c}\text { Off-pump } \\
(n=2335)\end{array}$ & \\
\hline Age at surgery (y) & & & & $<.0001$ \\
\hline $20-44$ & 6.3 & 6.5 & 5.7 & \\
\hline $45-64$ & 46.2 & 47.1 & 42.4 & \\
\hline $65-74$ & 32.6 & 32.4 & 33.7 & \\
\hline$\geq 75$ & 14.8 & 14.0 & 18.1 & \\
\hline Sex & & & & .5588 \\
\hline Men & 61.9 & 62.0 & 61.4 & \\
\hline Women & 38.1 & 38.0 & 38.6 & \\
\hline Race & & & & .1169 \\
\hline White & 65.4 & 65.6 & 64.8 & \\
\hline African-American & 28.0 & 28.1 & 27.8 & \\
\hline Other & 6.5 & 6.3 & 7.5 & \\
\hline ESRD etiology & & & & .2502 \\
\hline Diabetes & 57.6 & 57.7 & 56.9 & \\
\hline Hypertension & 24.0 & 23.7 & 25.3 & \\
\hline Other & 18.4 & 18.5 & 17.8 & \\
\hline ESRD duration (y) & & & & .4517 \\
\hline$<1$ & 21.1 & 21.1 & 21.4 & \\
\hline $1-<3$ & 33.1 & 33.2 & 32.3 & \\
\hline $3-<5$ & 22.1 & 21.9 & 23.2 & \\
\hline$\geq 5$ & 23.7 & 23.8 & 23.1 & \\
\hline Prior transplant & 5.6 & 5.7 & 5.0 & .1813 \\
\hline Peritoneal dialysis & 8.5 & 8.6 & 7.9 & .2605 \\
\hline Year of surgery & & & & $<.0001$ \\
\hline 2001 & 16.0 & 17.1 & 10.7 & \\
\hline 2002 & 17.6 & 18.0 & 16.2 & \\
\hline 2003 & 16.8 & 16.6 & 17.5 & \\
\hline 2004 & 17.3 & 16.8 & 19.9 & \\
\hline 2005 & 16.6 & 16.3 & 18.2 & \\
\hline 2006 & 15.6 & 15.2 & 17.5 & \\
\hline LOS for surgery (d) & & & & .1013 \\
\hline$<9$ & 23.1 & 22.8 & 24.8 & \\
\hline $9-<12$ & 21.6 & 21.5 & 22.1 & \\
\hline $12-<18$ & 29.2 & 29.4 & 28.5 & \\
\hline$\geq 18$ & 26.0 & 26.3 & 24.6 & \\
\hline $\begin{array}{c}\text { Number of vessels } \\
\text { bypassed }\end{array}$ & & & & $<.0001$ \\
\hline 1 & 7.8 & 6.3 & 14.3 & \\
\hline 2 & 19.7 & 18.0 & 27.2 & \\
\hline 3 & 36.7 & 37.1 & 34.6 & \\
\hline$\geq 4$ & 35.9 & 38.5 & 23.8 & \\
\hline Internal thoracic graft & 76.5 & 75.5 & 81.0 & $<.0001$ \\
\hline Comorbid conditions & & & & \\
\hline AMI & 53.9 & 54.2 & 52.4 & .1083 \\
\hline Cancer & 6.9 & 6.8 & 7.5 & .1807 \\
\hline Cardiac, other & 61.8 & 61.6 & 62.9 & .2630 \\
\hline CHF & 72.6 & 72.7 & 72.2 & .6420 \\
\hline COPD & 27.5 & 27.4 & 27.8 & .7473 \\
\hline CVA/TIA & 28.3 & 28.1 & 29.0 & .4114 \\
\hline Diabetes & 74.2 & 74.3 & 73.6 & .4677 \\
\hline Dysrhythmia & 54.1 & 53.9 & 55.1 & .2909 \\
\hline
\end{tabular}

TABLE 1. Continued

\begin{tabular}{lcccc}
\hline & \multicolumn{4}{c}{ Coronary artery } \\
& \multicolumn{3}{c}{ bypass graft surgery } & \\
\cline { 2 - 4 } & All & $\begin{array}{c}\text { On-pump } \\
\text { Characteristics }\end{array}$ & $\begin{array}{c}\text { Off-pump } \\
(\mathbf{n}=\mathbf{1 3 , 0 8 5})\end{array}$ & \\
$(\mathbf{n}=\mathbf{1 0 , 7 5 0})$ & $(\mathbf{n = 2 3 3 5 )}$ & $\boldsymbol{P}^{*}$ \\
\hline $\begin{array}{l}\text { Gastrointestinal } \\
\text { bleeding }\end{array}$ & 10.7 & 10.6 & 11.4 & .2299 \\
Liver disease & & & & \\
PVD & 8.3 & 8.3 & 8.1 & .7241 \\
\hline
\end{tabular}

Values are percents unless otherwise indicated. $A M I$, Acute myocardial infarction; $C H F$, congestive heart failure; $C O P D$, chronic obstructive pulmonary disease; $C V A$, cerebrovascular accident; TIA, transient ischemic attack; ESRD, end-stage renal disease; $L O S$, length of stay; $P V D$, peripheral vascular disease. *Using the chi-square test.

were likely to have fewer coronary arteries bypassed than patients having on-pump CABG. Interestingly, although internal thoracic graft use was high in both groups, it was significantly higher for patients having OPCAB.

The number of patients having OPCAB increased progressively from 2001 to 2006 , likely reflecting improved operator expertise, more published literature and increased awareness regarding $\mathrm{OPCAB}$, and technological advances in the field including development of mechanical stabilization and cardiac positioning devices for OPCAB. The mean length of stay during the CABG surgery hospitalization was similar in both groups (15.32 days for OPCAB versus 15.73 days for on-pump CABG, $P=.17$ ). The median length of stay was 12 days in both study groups.

In-hospital mortality was $9.7 \%$ for patients having OPCAB and $11.0 \%$ for patients having on-pump CABG $(P=.06)$. Figure 1 presents the Kaplan-Meier curves for all-cause survival for patients having OPCAB and patients having on-pump CABG. The observed benefit of OPCAB on all-cause survival was most notable in the first 12 months after surgery. The estimated all-cause survival rates for patients having OPCAB and patients having on-pump CABG, respectively, were $90.4 \%$ versus $88.5 \%$ $(P=.0087)$ at 30 days, $78.2 \%$ versus $76.5 \%(P=.07)$ at 6 months, $70.3 \%$ versus $68.7 \%(P=.10)$ at 1 year, $55.4 \%$ versus $55.2 \%$ at 2 years, and $42.1 \%$ versus $42.3 \%$ at 3 years. After adjustment for baseline patient characteristics, OPCAB was associated with an $8 \%$ reduction in death compared with on-pump CABG (hazard ratio, 0.92; $95 \%$ confidence interval $[\mathrm{CI}], 0.86-0.99 ; P=.02)$.

When the combined event of second CABG and death was examined via Cox proportional hazards model, $\mathrm{OPCAB}$ continued to be associated with a statistically significant reduction in second CABG or death compared with on-pump CABG (hazard ratio, 0.92; 95\% CI, 0.86-0.98; $P=.01$ ). For the end point of second CABG alone, we found no difference between the 2 groups $(P=.22)$.

We also evaluated first claim for percutaneous coronary intervention (PCI) after the admission for CABG surgery. In the OPCAB group 103 patients $(4.41 \%)$ and in the 


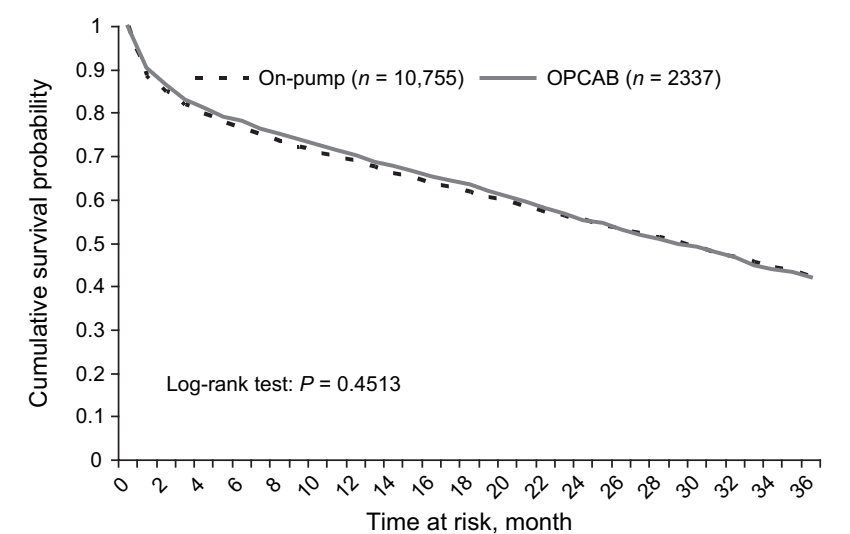

No. of pts. at risk

OPCAB 2337

On-pump 10,755



5995

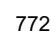

3702

394

2053

FIGURE 1. All-cause survival of patients on dialysis having off-pump and on-pump coronary artery bypass surgery between 2001 and 2006. OPCAB, Off-pump coronary artery bypass.

on-pump CABG group 346 patients $(3.22 \%$ ) had PCI during the hospitalization for CABG surgery. Further analysis of the timing of these procedures revealed that most preceded the CABG surgery. This finding likely reflects CABG surgery occurring in the context of complicated or unsuccessful PCI. In the OPCAB group 221 patients $(9.47 \%)$ and in the on-pump CABG group 876 patients $(8.15 \%)$ had PCI after the hospitalization for CABG surgery. In the OPCAB group 123 patients $(5.27 \%)$ had PCI within 1 year of the hospitalization and 98 patients $(4.19 \%)$ after 1 year. In the on-pump CABG group 473 patients $(4.4 \%)$ had PCI within 1 year of the hospitalization and 403 patients $(3.75 \%)$ after 1 year. The distribution of timing of the first PCI procedure relative to the hospitalization for CABG surgery (during, within 1 year, and after 1 year) between groups was statistically significant $(P=.0037)$.

Advanced age, diabetic ESRD, dialysis duration, peritoneal dialysis, and cardiovascular comorbid conditions (congestive heart failure, myocardial infarction, and peripheral vascular disease) were identified as independent predictors of all-cause mortality (Table 2). Consistent with prior publications on coronary revascularization, survival was better for African-American patients on dialysis than for white patients on dialysis. ${ }^{13}$ Interestingly, single-vessel CABG versus multivessel $\mathrm{CABG}$ was noted to be an independent predictor of mortality, perhaps reflecting incomplete revascularization. Concordant with prior data on CABG in the general population, use of internal thoracic grafts was associated with an $8 \%$ reduction in mortality (hazard ratio, 0.92 ; 95\% CI, 0.87-0.98; $P=.0057)$.

The adjusted hazards ratio of cardiac mortality for OPCAB versus on-pump CABG was 0.95 (95\% CI, 0.86$1.04 ; P=.26)$. The observed benefit of OPCAB on cardiac survival was most notable in the first 6 months after surgery and diminished after 12 months. The estimated cardiac survival rates for patients having OPCAB and patients having on-pump CABG, respectively, were $93.8 \%$ versus $92.4 \%$ $(P=.02)$ at 30 days, $87.6 \%$ versus $86.3 \%(P=.09)$ at 6 months, $82.6 \%$ versus $82.2 \%$ at 1 year, $73.4 \%$ versus $74.2 \%$ at 2 years, and $64.1 \%$ versus $65.5 \%$ at 3 years.

Of the 2335 patients having OPCAB, $110(4.7 \%)$ had claims with CPT code 00562 (with pump oxygenator) during the same hospitalization, suggesting crossover to an on-pump CABG procedure. The Kaplan-Meier survival estimates at 30 days for the crossover OPCAB group, the OPCAB-only group, and the on-pump CABG group were $88.1 \%, 90.5 \%$, and $88.5 \%$ respectively ( $P$ value by $\log -$ rank test $=.024)$. The survival advantage for the OPCABonly group was lost at 6 months after the surgery.

\section{DISCUSSION}

Patients on dialysis constitute an extremely high-risk population with respect to outcomes following CABG surgery; Herzog and colleagues ${ }^{13}$ previously reported in-hospital mortality of $8.6 \%$ and 2-year mortality of $44 \%$. Using the Society of Thoracic Surgeons database, Cooper and associates ${ }^{19}$ noted an operative mortality rate of $9 \%$ for dialysisdependent patients having CABG surgery, with a marked incremental increase in mortality with worsening glomerular filtration rates. Due to the possible benefit of OPCAB for high-risk populations, it is reasonable to evaluate its use in patients on dialysis as a potential strategy to reduce mortality associated with CABG. Manabe and coworkers ${ }^{20}$ suggested a physiologic basis for supporting OPCAB in patients on hemodialysis by demonstrating improved cardiac hemodynamics in the form of postoperative reduction in right atrial and pulmonary capillary wedge pressure and improvement in postoperative lung oxygenation compared with patients having on-pump $\mathrm{CABG}$.

We found an $8 \%$ risk reduction in all-cause mortality associated with OPCAB in patients on dialysis. This modest benefit was noted primarily in the first year after surgery, likely reflecting the advantages of the surgical technique itself in preventing deleterious inflammatory, vascular, and embolic consequences of cardiopulmonary bypass in various organ beds, ${ }^{5,6}$ combined with a postulated favorable early effect on cardiac hemodynamics. ${ }^{20}$ Because patients on dialysis constitute an extremely high-risk population with regard to operative and long-term mortality, this benefit might be attenuated. The high rates of noncardiac mortality we noted point to the complex noncardiac morbidity in this population. This is further reflected by the longer hospital stays for patients on dialysis despite OPCAB use in this study, contrary to observations from previous studies in the general population.

Few studies have previously assessed the impact of OP$\mathrm{CAB}$ on mortality in patients on dialysis. ${ }^{14,15,21-23}$ Dewey and colleagues ${ }^{14}$ studied 158 patients on hemodialysis; 
TABLE 2. Cox proportional hazards model for independent predictors of all-cause mortality in patients on dialysis having coronary artery bypass graft surgery

\begin{tabular}{|c|c|c|}
\hline Characteristics & Hazard ratio $(95 \% \mathrm{CI}) *$ & $P$ \\
\hline Off-pump CABG surgery & $0.92(0.86-0.99)$ & .018 \\
\hline \multicolumn{3}{|l|}{ Age at surgery (y) } \\
\hline $20-44$ & $0.89(0.79-1.02)$ & .085 \\
\hline $65-74$ & $1.27(1.20-1.35)$ & $<.0001$ \\
\hline$\geq 75$ & $1.67(1.55-1.80)$ & $<.0001$ \\
\hline \multicolumn{3}{|l|}{ Sex } \\
\hline Women & $1.13(1.07-1.19)$ & $<.0001$ \\
\hline \multicolumn{3}{|l|}{ Race } \\
\hline African-American & $0.88(0.83-0.94)$ & $<.0001$ \\
\hline Other race & $0.96(0.86-1.07)$ & .4179 \\
\hline \multicolumn{3}{|l|}{ ESRD duration (y) } \\
\hline$<1$ & $0.86(0.79-0.92)$ & $<.0001$ \\
\hline $3-<5$ & $1.21(1.13-1.29)$ & $<.0001$ \\
\hline$\geq 5$ & $1.35(1.25-1.45)$ & $<.0001$ \\
\hline \multicolumn{3}{|l|}{ ESRD etiology } \\
\hline Diabetes & $1.24(1.13-1.35)$ & $<.0001$ \\
\hline Hypertension & $1.14(1.05-1.23)$ & .0021 \\
\hline Prior transplant & $0.97(0.85-1.11)$ & .6515 \\
\hline Peritoneal dialysis & $1.47(1.35-1.61)$ & $<.0001$ \\
\hline \multicolumn{3}{|l|}{ Year of surgery } \\
\hline 2001 & $1.17(1.04-1.32)$ & .007 \\
\hline 2002 & $1.16(1.03-1.29)$ & .0128 \\
\hline 2003 & $1.08(0.97-1.21)$ & .1757 \\
\hline 2004 & $1.06(0.95-1.19)$ & .2940 \\
\hline 2005 & $1.08(0.96-1.22)$ & .1991 \\
\hline Internal thoracic graft & $0.92(0.87-0.98)$ & .0057 \\
\hline \multicolumn{3}{|l|}{ Number of vessels bypassed } \\
\hline 1 & $1.29(1.18-1.42)$ & $<.0001$ \\
\hline 2 & $1.16(1.08-1.24)$ & $<.0001$ \\
\hline 3 & $1.02(0.96-1.08)$ & .6184 \\
\hline \multicolumn{3}{|l|}{ LOS for surgery (d) } \\
\hline $9-<12$ & $0.88(0.81-0.95)$ & .0023 \\
\hline $12-<18$ & $0.94(0.87-1.01)$ & .0999 \\
\hline$\geq 18$ & $1.37(1.27-1.48)$ & $<.0001$ \\
\hline \multicolumn{3}{|l|}{ Comorbid conditions } \\
\hline AMI & $1.24(1.17-1.30)$ & $<.0001$ \\
\hline Cancer & $1.07(0.97-1.17)$ & .1771 \\
\hline Cardiac, other & $1.15(1.08-1.21)$ & $<.0001$ \\
\hline CHF & $1.30(1.21-1.39)$ & $<.0001$ \\
\hline COPD & $1.24(1.17-1.31)$ & $<.0001$ \\
\hline CVA/TIA & $1.23(1.16-1.29)$ & $<.0001$ \\
\hline Diabetes & $1.06(0.97-1.14)$ & .1874 \\
\hline Dysrhythmia & $1.41(1.33-1.49)$ & $<.0001$ \\
\hline Gastrointestinal bleeding & $1.15(1.07-1.24)$ & .0002 \\
\hline Liver disease & $1.20(1.10-1.31)$ & $<.0001$ \\
\hline PVD & $1.32(1.25-1.39)$ & $<.0001$ \\
\hline
\end{tabular}

$A M I$, Acute myocardial infarction; $C A B G$, coronary artery bypass graft; $C H F$, congestive heart failure; $C I$, confidence interval; $C O P D$, chronic obstructive pulmonary disease; $C V A$, cerebrovascular accident; $T I A$, transient ischemic attack; $E S R D$, end-stage renal disease; $L O S$, length of stay; $P V D$, peripheral vascular disease. ${ }^{*}$ Reference groups: ages 45-64 years, men, white race, other cause of ESRD, ESRD duration $1-<3$ years, no prior transplantation, hemodialysis modality, year of surgery 2006 , no internal thoracic graft, 4 vessels bypassed, length of stay $<9 \mathrm{~d}$; no comorbid conditions.
$37.3 \%$ had OPCAB. The authors reported a mortality benefit with $\mathrm{OPCAB}$, but it should be noted that the perioperative mortality in their OPCAB group was extraordinarily low at $1.7 \%$ versus $17.2 \%$ for the on-pump CABG control group. Beckermann and associates ${ }^{15}$ studied 3922 patients in the USRDS database; $13.8 \%$ had OPCAB in a 2-year entry period. The authors reported a $14 \%$ risk reduction in all-cause mortality for the OPCAB group compared with the on-pump CABG group, but the researchers did not assess the potentially important effect of number of vessels bypassed. Moreover, the sample size in the current study is approximately 3 times larger, with length-of-stay information and more recent patient data, compared with the study by Beckermann and colleagues. ${ }^{15}$

OPCAB may also confer short-term benefit in the general population. Hannan and coworkers ${ }^{24}$ reported a significant $19 \%$ reduction in inpatient and 30-day mortality using New York state registry data. In a meta-analysis of 14 non-randomized trials, Panesar and colleagues ${ }^{25}$ showed a marked reduction in in-hospital mortality rates, especially among octogenarians. In another meta-analysis, Wijeysundera and colleagues ${ }^{26}$ found a short-term mortality advantage in observational studies but not randomized studies.

Similar to our study, previous studies have demonstrated that the early benefit of OPCAB disappears in the long term. In a large retrospective study, Hannan and associates ${ }^{24}$ found that 3-year mortality rates with $\mathrm{OPCAB}$ were comparable to on-pump CABG. Further, concerns have been raised regarding $\mathrm{OPCAB}$ and the long-term adequacy of revascularization. ${ }^{24,26,27} \mathrm{We}$ found no significant difference in occurrence of second CABG for OPCAB versus on-pump CABG. Reassuringly, we found no increase in mortality for patients having OPCAB in longer follow-up.

Only $17.8 \%$ of our study group had OPCAB over 6 years, less than the $25 \%$ to $30 \%$ OPCAB use in the general population in New York state. ${ }^{24,28}$ Although there has been a slight interval increase in the percentage of patients on dialysis who now have $\mathrm{OPCAB}(17.8 \%$ in the current study vs $14 \%$ in $2001-2002),{ }^{15}$ OPCAB is relatively underused in this high-risk patient population compared with the general population.

Our study has several limitations. The retrospective nature of the evaluation introduces the possibility of selection bias. The USRDS database consists predominantly of administrative data. Clinical variables such as left ventricular ejection fraction, functional class, coronary arteriographic data, and degree of aortic calcification could not be studied. Previous studies have reported a higher mortality rate following a crossover or conversion from OPCAB to an on-pump procedure. ${ }^{29}$ Thus, we attempted to assess the number of patients who crossed over, but the method we used may have underestimated the crossover rate.

In summary, this study represents the largest number of patients on long-term dialysis for whom $\mathrm{OPCAB}$ and 
on-pump CABG outcomes have been compared. Our findings indicate that patients on dialysis are a high-risk population and sustain very high in-hospital and 2-year mortality rates. Patients on dialysis may benefit from OPCAB by reduced early mortality compared with on-pump CABG. Randomized controlled trials are needed in this high-risk patient population to ascertain the strength of this benefit. Based on our observational data, OPCAB for patients on dialysis who have $\mathrm{CABG}$ surgery may offer a modest benefit in outcome.

We thank United States Renal Data System colleagues Shane Nygaard, BA, for manuscript preparation, and Nan Booth, MSW, $\mathrm{MPH}$, for manuscript editing.

\section{References}

1. Go AS, Chertow GM, Fan D, McCulloch CE, Hsu CY. Chronic kidney disease and the risks of death, cardiovascular events, and hospitalization. $N$ Engl J Med. 2004;351:1296-305.

2. U.S. Renal Data System. USRDS 2008 Annual Data Report: Atlas of Chronic Kidney Disease \& End-Stage Renal Disease in the United States. Bethesda, MD: National Institutes of Health, National Institute of Diabetes and Digestive and Kidney Diseases; 2008.

3. Herzog C, Gilbertson D. Comparative long-term survival of general Medicare patients with surgical versus percutaneous coronary intervention in the era of drug-eluting stents and impact of chronic kidney disease. Circulation. 2008;118(Suppl 2):S741.

4. Herzog C, Solid C. Long-term survival of U.S. dialysis patients after surgical bypass or percutaneous coronary stent placement in the drug-eluting stent era. $J A m$ Soc Nephrol. 2008;91:11A.

5. Raja SG, Berg GA. Impact of off-pump coronary artery bypass surgery on systemic inflammation: current best available evidence. J Card Surg. 2007;22:445-55.

6. Blauth CI, Cosgrove DM, Webb BW, Ratliff NB, Boylan M, Piedmonte MR, et al. Atheroembolism from the ascending aorta. An emerging problem in cardiac surgery. J Thorac Cardiovasc Surg. 1992;103:1104-11.

7. Magee MJ, Coombs LP, Peterson ED, Mack MJ. Patient selection and current practice strategy for off-pump coronary artery bypass surgery. Circulation. 2003;108(Suppl 1):II9-14.

8. Mack MJ, Pfister A, Bachand D, Emery R, Magee MJ, Connolly M, et al. Comparison of coronary bypass surgery with and without cardiopulmonary bypass in patients with multivessel disease. J Thorac Cardiovasc Surg. 2004;127:167-73.

9. Legare JF, Buth KJ, King S, Wood J, Sullivan JA, Hancock FC, et al. Coronary bypass surgery performed off pump does not result in lower in-hospital morbidity than coronary artery bypass grafting performed on pump. Circulation. 2004;109: 887-92.

10. Nathoe HM, van DD, Jansen EW, Suyker WJ, Diephuis JC, van Boven WJ, et al. A comparison of on-pump and off-pump coronary bypass surgery in low-risk patients. N Engl J Med. 2003;348:394-402.

11. Racz MJ, Hannan EL, Isom OW, Subramanian VA, Jones RH, Gold JP, et al. A comparison of short- and long-term outcomes after off-pump and on-pump coronary artery bypass graft surgery with sternotomy. J Am Coll Cardiol. 2004;43:557-64.

12. Al-Ruzzeh S, Ambler G, Asimakopoulos G, Omar RZ, Hasan R, Fabri B, et al. Off-pump coronary artery bypass (OPCAB) surgery reduces risk-stratified morbidity and mortality: a United Kingdom Multi-Center Comparative Analysis of Early Clinical Outcome. Circulation. 2003;108(Suppl 1):II1-8.
13. Herzog CA, Ma JZ, Collins AJ. Comparative survival of dialysis patients in the United States after coronary angioplasty, coronary artery stenting, and coronary artery bypass surgery and impact of diabetes. Circulation. 2002;106: 2207-11.

14. Dewey TM, Herbert MA, Prince SL, Robbins CL, Worley CM, Magee MJ, et al. Does coronary artery bypass graft surgery improve survival among patients with end-stage renal disease? Ann Thorac Surg. 2006;81:591-8.

15. Beckermann J, Van CJ, Li S, Wahl SK, Collins A, Herzog CA. On-pump versus off-pump coronary surgery outcomes in patients requiring dialysis: perspectives from a single center and the United States experience. $J$ Thorac Cardiovasc Surg. 2006;131:1261-6.

16. United States Renal Data System. 1992 Annual Data Report. Analytical methods: technical notes. Am J Kidney Dis. 1992;20(5 Suppl. 2):100-7.

17. Collins AJ, Ma J, Constantini E, Everson S. Dialysis unit and patient characteristics associated with reuse practices and mortality: 1989-1993. J Am Soc Nephrol. 1998;9:2108-17.

18. Hebert PL, Geiss LS, Tierney EF, Engelgau MM, Yawn BP, McBean AM. Identifying persons with diabetes using Medicare claims data. Am J Med Qual. 1999; 14:270-7.

19. Cooper WA, O'Brien SM, Thourani VH, Guyton RA, Bridges CR, Szczech LA, et al. Impact of renal dysfunction on outcomes of coronary artery bypass surgery: results from the Society of Thoracic Surgeons National Adult Cardiac Database. Circulation. 2006;113:1063-70.

20. Manabe S, Arai H, Tanaka H, Tabuchi N, Sunamori M. Physiological comparison of off-pump and on-pump coronary artery bypass grafting in patients on chronic hemodialysis. Jpn J Thorac Cardiovasc Surg. 2006;54:3-10.

21. Moore GJ, Trachiotis GD. Outcomes of off-pump versus on-pump coronary artery bypass surgery in end-stage renal disease patients with a history of myocardial infarction. Heart Surg Forum. 2006;9:E774-8.

22. Horai T, Fukui T, Tabata M, Takanashi S. Early and mid-term results of off-pump coronary artery bypass grafting in patients with end stage renal disease: surgical outcomes after achievement of complete revascularization. Interact Cardiovasc Thorac Surg. 2008;7:218-21.

23. Murai N, Kodera K, Sasaki A, Asano R, Kataoka G, Ikeda M, et al. Prognosis after off-pump coronary artery bypass in patients receiving hemodialysis. Ann Thorac Cardiovasc Surg. 2007;13:396-9.

24. Hannan EL, Wu C, Smith CR, Higgins RS, Carlson RE, Culliford AT, et al. Offpump versus on-pump coronary artery bypass graft surgery: differences in shortterm outcomes and in long-term mortality and need for subsequent revascularization. Circulation. 2007;116:1145-52.

25. Panesar SS, Athanasiou T, Nair S, Rao C, Jones C, Nicolaou M, et al. Early outcomes in the elderly: a meta-analysis of 4921 patients undergoing coronary artery bypass grafting — comparison between off-pump and on-pump techniques. Heart. 2006;92:1808-16.

26. Wijeysundera DN, Beattie WS, Djaiani G, Rao V, Borger MA, Karkouti K, et al. Off-pump coronary artery surgery for reducing mortality and morbidity: metaanalysis of randomized and observational studies. J Am Coll Cardiol. 2005;46: 872-82.

27. Lim E, Drain A, Davies W, Edmonds L, Rosengard BR. A systematic review of randomized trials comparing revascularization rate and graft patency of off-pump and conventional coronary surgery. J Thorac Cardiovasc Surg. 2006;132: 1409-13.

28. Lytle BW. On-pump and off-pump coronary bypass surgery. Circulation. 2007; 116:1108-9.

29. Legare JF, Buth KJ, Hirsch GM. Conversion to on pump from OPCAB is associated with increased mortality: results from a randomized controlled trial. Eur J Cardiothorac Surg. 2005;27:296-301. 